\title{
Clinical Reasoning: A 36-Year-Old Woman Presenting With Headache Postpartum
}

Ahmad Nehme, MD, Laurent Létourneau-Guillon, MD, Céline Odier, MD, and Alexandre Y. Poppe, MD, CM Neurology ${ }^{\circledR}$ 2021;96:e1585-e1589. doi:10.1212/WNL.0000000000011318
Correspondence

A. Nehme

Ahmad.nehme@

umontreal.ca

\section{Section 1}

A 36-year-old healthy G2P2 woman presented on postpartum day 10 with severe headache, progressing over several hours. She had no history of migraines and used neither medications nor drugs. The headache was not postural. She reported no associated neurologic symptoms or trauma. She described chest pain radiating to the thoracic spine, without visual changes, abdominal pain, or lower limb edema. Blood pressure (BP) was 166/94 mm Hg. She was afebrile. Mental status was normal. Examination revealed mild neck stiffness, without papilledema or focal neurologic deficits. Deep tendon reflexes were symmetrically brisk. Investigations showed no anemia, thrombocytopenia, liver dysfunction, or proteinuria. ECG and thoracic CT angiogram (CTA) were normal.

The patient underwent a C-section 4 years earlier due to fetal bradycardia during labor. She received prophylactic aspirin up to week 36 of her most recent pregnancy, as she had 2 moderate risk factors for preeclampsia (age $\geq 35$ and Afro-Caribbean origin). ${ }^{1} \mathrm{BP}$ was normal throughout pregnancy. At week 39, an uncomplicated L2-L3 epidural anesthesia and an elective C-section were performed.

\section{Question for Consideration:}

1. What is the differential diagnosis of postpartum headache?

GO TO SECTION 2 


\section{Section 2}

Postpartum headaches are more often secondary than primary among women for whom acute neurologic consultation is performed. ${ }^{2}$ Postpartum hypertensive disorders of pregnancy (preeclampsia and eclampsia) manifest with new-onset BP $>140 / 90 \mathrm{~mm} \mathrm{Hg}$ and organ dysfunction, which includes symptoms of neurologic origin and moderate to severe headache that does not respond to simple analgesia. Neurovascular diseases-such as ischemic stroke, intracranial hemorrhage, cervicocephalic artery dissection, cerebral venous thrombosis, reversible cerebral vasoconstriction syndrome (RCVS), and posterior reversible encephalopathy syndrome (PRES) - develop more often in the postpartum period. Improvement of headache in the supine position suggests post-dural puncture intracranial hypotension. Lymphocytic hypophysitis and Sheehan syndrome can present with visual loss and pituitary gland failure. Primary etiologies (migraine, tension) also occur, in part because of stress and sleep deprivation.
Due to new-onset hypertension and brisk reflexes, the patient was initially diagnosed with postpartum preeclampsia. IV labetalol and IV magnesium were initiated, and she transferred to our institution. Chest pain resolved, but headache persisted, and nuchal rigidity suggested an alternative etiology. Head CT the following day demonstrated bilateral parieto-occipital subarachnoid hemorrhage (SAH) (figure 1A). Head CTA revealed dissections of the right extracranial and left intracranial and extracranial vertebral arteries, with no evidence of fibromuscular dysplasia (figure 1B). The patient reported no neck pain before postpartum day 10 . The left intracranial vertebral dissection led to a $70 \%$ stenosis of the artery. The remaining intracranial arteries were normal. Brain MRI with T1 fat suppression confirmed intramural hematomas at the dissection sites and excluded cerebral infarction (figure 1C).

\section{Questions for Consideration:}

1. What could explain the SAH?

2. How would you treat the intracranial vertebral artery dissection?

Figure 1 Subarachnoid Hemorrhage and Cervicocephalic Artery Dissections

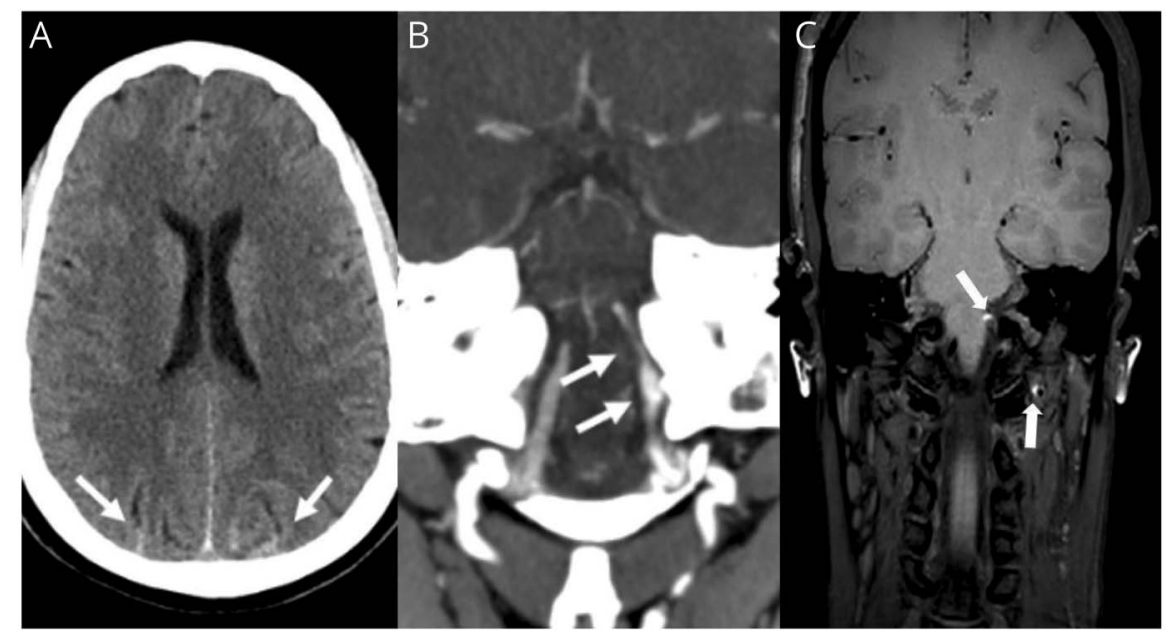

(A) Axial noncontrast head CT reveals bilateral parietal cortical subarachnoid hemorrhage. (B) Coronal head CT angiogram demonstrates fusiform ectasia followed by narrowing of the intradural left vertebral artery, consistent with a dissection. Additional bilateral extracranial vertebral artery dissections were also identified (not shown). (C) Coronal brain MRI with T1 fat suppression identifies hyperintensities that correspond to intramural hematomas, which confirms dissections of the left intracranial and extracranial vertebral arteries. The right extracranial vertebral intramural hematoma is not shown.

\section{GO TO SECTION 3}




\section{Section 3}

Intracranial arteries have a well-developed internal but no external elastic lamina, which makes them susceptible to subadventitial dissection and secondary SAH. RCVS can initially present with convexity $\mathrm{SAH}$, and vasospasm can be absent if imaging is performed in the first week after headache onset. Cervicocephalic artery dissection more often coexists with PRES or RCVS in postpartum vs nonpostpartum women. ${ }^{3}$ Intracranial aneurysms, vascular malformations, and cerebral venous thrombosis should also be considered.

In our patient, the left intracranial vertebral artery dissection was the most likely cause of SAH. As the risk of rebleeding after SAH due to intracranial dissection approaches $40 \%$, surgical or endovascular treatment is usually considered. ${ }^{4}$ Medical treatment-often antiplatelet agents-is preferred when patients present only with pain or cerebral ischemia, as the risk of subsequent SAH is considered low. ${ }^{4}$

In our case, there was concern that, if we occluded the left vertebral artery, progression of the right vertebral dissection might lead to bilateral vertebral occlusion. On angiography, the right extracranial vertebral dissection was stable and nonstentotic. Injection of the right vertebral artery showed retrograde filling of the left vertebral artery. Both posterior communicating nonstenotic arteries were patent, and no vasospasm was seen. Consequently, to prevent recurrent SAH, we performed endovascular occlusion of the left intracranial vertebral artery. We initiated aspirin to prevent thrombus formation at the remaining extracranial dissection sites.

On postpartum day 16, transcranial Doppler revealed increased systolic velocities and prompted a head CTA that showed diffuse post-SAH vasospasm, which we treated with oral nimodipine (figure 2A). Blood workup for systemic causes of vasculitis was negative.

The next day, the patient reported lower limb paresthesias, without weakness or sensory level on examination. Since admission, she had required urinary catheterization.

\section{Question for Consideration:}

1. What is the next step in the investigation?

Figure 2 CT Angiogram and Spinal Imaging

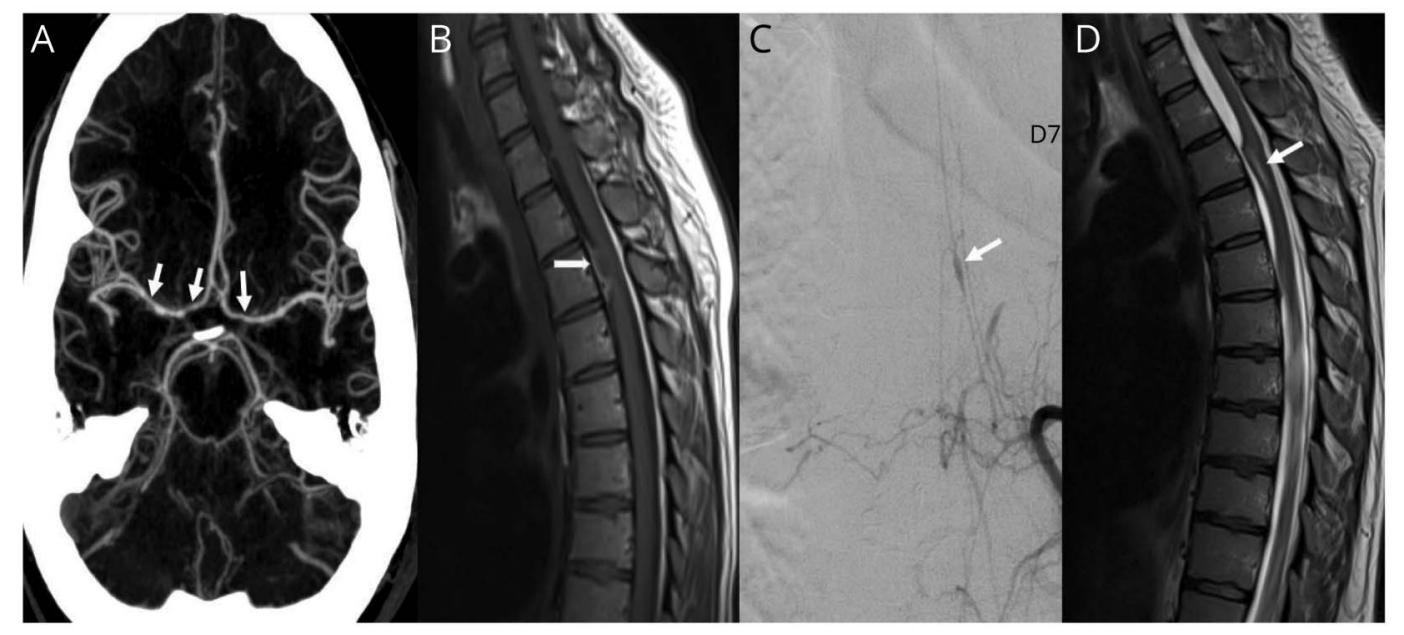

(A) Follow-up axial head CT angiogram, on postpartum day 16, shows diffuse segmental narrowing of intracranial arteries compatible with vasospasm. (B) Sagittal T1 image on MRI at the T3 level demonstrates a heterogenous intradural-extramedullary lesion, associated with cord compression, in keeping with an intradural hematoma. (C) Left T7 arteriogram reveals an aneurysm of the radiculo-medullary artery of Adamkiewicz. (D) Sagittal T2 image on MRI obtained at the T3 level at 3 months shows adhesive arachnoiditis with distortion of the spinal cord and secondary intramedullary signal changes.

\section{GO TO SECTION 4}




\section{Section 4}

Sphincter dysfunction and bilateral lower limbs paresthesias suggest a spinal cord lesion. Spine MRI revealed a T1hyperintense, T2-hypointense, nonenhancing intradural extramedullary lesion at the T3 level, suggestive of a hematoma. This was associated with a dependent blood-CSF level at the thecal sac and compatible with spinal SAH (figure 2B). Epidural anesthesia was performed several levels lower and could not explain the hematoma. Spinal angiography identified 2 fusiform aneurysms on left radicular branches of $\mathrm{T} 3$ and T7 (figure 2C).

Spinal aneurysms can develop with diseases that increase blood flow to the spinal circulation (arteriovenous malformation) or that compromise the vessel wall (connective tissue disorders, vasculitis). They may also result from arterial dissection. ${ }^{5}$ While there was no direct evidence of radicular artery dissection in our case, the co-occurrence of vertebral dissections supports this hypothesis. The initial episode of chest pain was perhaps secondary to dissection of a radicular artery and subsequent spinal SAH. In retrospect, the parietooccipital SAH may have represented redistribution of spinal $\mathrm{SAH}$, or may have resulted from intracranial vertebral artery dissection, as we initially hypothesized. Rebleed rates and optimal management of spinal aneurysms are unknown. We elected for a conservative approach and discontinued aspirin. We did not perform a lumbar puncture due to the risk of downward spinal coning when a compressive cord lesion is present.

Headache resolved 1 week later. We prescribed calcium channel blockers for 3 months to address the vasospasm. The patient was discharged home postpartum day 22 but readmitted 3 months later for gait difficulties, progressing over several weeks. Urinary retention had resolved. Examination of the lower limbs revealed increased tone, symmetrically decreased strength (4/5), and bilaterally diminished pinprick sensation up to $\mathrm{T} 8$.

\section{Question for Consideration:}

1. What could explain the delayed-onset gait difficulties? 


\section{Section 5}

Spastic paraparesis and a sensory level suggest a spinal cord lesion. Rebleed from spinal aneurysms would likely lead to a more abrupt onset of symptoms. Following spinal SAH, altered CSF dynamics predispose to syringomyelia. Chronic subarachnoid bleeding can cause superficial siderosis, with hemosiderin accumulation around the spinal cord. Subarachnoid blood can trigger a chronic inflammatory reaction of the arachnoid membrane. This spinal arachnoiditis may deform the spinal cord, resulting in compressive myelopathy.

Spine MRI revealed T2 hypersignal and distortion of the cord at the T3 level, as well as multiple sites of adhesions, suggestive of arachnoiditis (figure 2D). There were no residual aneurysms on spinal angiography. Head CTA demonstrated resolution of the vasospasm and normalization of the initially dissected segments of both extracranial vertebral arteries. The patient underwent surgical lysis of adherences and was discharged to rehabilitation.

At 6-month follow-up, she required a walking aid due to moderate spastic paraparesis. A multigene connective tissue disease panel was normal.

\section{Discussion}

Numerous reports highlight the association between the postpartum period and RCVS, PRES, and cervicocephalic artery dissection. ${ }^{3}$ Postpartum angiopathy historically referred to postpartum RCVS. Postpartum arteriopathies can develop with or without preeclampsia, which suggests that both share common pathophysiologic mechanisms.

In the Cervical Artery Dissection and Ischemic Stroke Patients registry, multiple cervical dissections occurred in $15 \%$ of cases and were associated with fibromuscular dysplasia and recent infections, both absent in our case. ${ }^{6}$ Another study found no underlying arteriopathy in patients with triple and quadruple cervical dissections. ${ }^{7}$ Dissection of multiple cervical arteries is not associated with a family history of dissection, which may be a surrogate marker for genetic connective tissue disorders. ${ }^{8}$ A recent case-control analysis identified pregnancy as a risk factor for cervical artery dissection, specifically in the postpartum period. ${ }^{9}$ Cases were diagnosed on average 21 days after labor, which suggests that the postpartum period may transiently predispose arteries to dissection. The effect of trauma during labor on this association is unknown, as the authors did not stratify cases by mode of delivery.

A ruptured spinal aneurysm during pregnancy has, to our knowledge, only been reported once postmortem. ${ }^{10}$ In our case, the spinal aneurysms likely resulted from the same fulminant arteriopathy that affected the cervicocephalic arteries. While impossible to prove, these were likely dissecting aneurysms, as they co-occurred with cervicocephalic artery dissections and resolved on follow-up vascular imaging.

A secondary etiology should always be ruled out in patients presenting with a new-onset postpartum headache. Spinal dissecting aneurysms may complicate cases of postpartum cervicocephalic artery dissection. Spinal SAH, though rare, should always be considered when unexplained cerebral SAH, back pain, or symptoms of spinal cord dysfunction are present. Clinicians should not systematically attribute spinal SAH to epidural anesthesia in postpartum women and spinal angiography may be a useful diagnostic test.

\section{Acknowledgment}

The authors thank the patient for consenting to the publication of this case.

\section{Study Funding}

No targeted funding reported.

\section{Disclosure}

The authors report no disclosures relevant to the manuscript. Go to Neurology.org/ $\mathrm{N}$ for full disclosures.

Appendix Authors

\begin{tabular}{lll}
\hline Name & Location & Contribution \\
\hline $\begin{array}{l}\text { Ahmad Nehme, } \\
\text { MD }\end{array}$ & $\begin{array}{l}\text { Université } \\
\text { de Montréal }\end{array}$ & $\begin{array}{l}\text { Drafting the manuscript, data } \\
\text { acquisition and analysis, design and } \\
\text { conceptualization of the study }\end{array}$ \\
\hline $\begin{array}{l}\text { Laurent } \\
\text { Létourneau- }\end{array}$ & $\begin{array}{l}\text { Université } \\
\text { de Montréal }\end{array}$ & $\begin{array}{l}\text { Data acquisition and revising the } \\
\text { manuscript }\end{array}$ \\
$\begin{array}{l}\text { Céline Odier, MD } \\
\text { Université } \\
\text { de Montréal }\end{array}$ & $\begin{array}{l}\text { Interpretation of the data and } \\
\text { revising the manuscript }\end{array}$ \\
$\begin{array}{l}\text { Alexandre Y. } \\
\text { Poppe, MD, CM }\end{array}$ & $\begin{array}{l}\text { Université } \\
\text { de Montréal }\end{array}$ & $\begin{array}{l}\text { Interpretation of the data and } \\
\text { revising the manuscript }\end{array}$ \\
\hline
\end{tabular}

\section{References}

1. ACOG Committee Opinion No. 743: low-dose aspirin use during pregnancy. Obstet Gynecol 2018;132:e44-e52.

2. Vgontzas A, Robbins MS. A hospital based retrospective study of acute postpartum headache. Headache 2018;58:845-851.

3. Arnold M, Camus-Jacqmin M, Stapf C, et al. Postpartum cervicocephalic artery dissection. Stroke 2008;39:2377-2379.

4. Ono H, Nakatomi H, Tsutsumi K, et al. Symptomatic recurrence of intracranial arterial dissections: follow-up study of 143 consecutive cases and pathological investigation. Stroke 2013;44:126-131.

5. Massand MG, Wallace RC, Gonzalez LF, et al. Subarachnoid hemorrhage due to isolated spinal artery aneurysm in four patients. Am J Neuroradiol 2005;26: 2415-2419.

6. Béjot $\mathrm{Y}$, Aboa-Eboulé C, Debette $\mathrm{S}$, et al. Characteristics and outcomes of patients with multiple cervical artery dissection. Stroke 2014;45:37-41.

7. Arnold M, De Marchis GM, Stapf C, et al. Triple and quadruple spontaneous cervical artery dissection: presenting characteristics and long-term outcome. J Neurol Neurosurg Psychiatry 2009;80:171-174.

8. Debette S, Goeggel Simonetti B, Schilling S, et al. Familial occurrence and heritable connective tissue disorders in cervical artery dissection. Neurology 2014;83: 2023-2031

9. Salehi Omran S, Parikh NS, Poisson S, et al. Association between pregnancy and cervical artery dissection. Ann Neurol Epub 2020 Jun 11.

10. Garcia CA, Dulcey S, Dulcey J. Ruptured aneurysm of the spinal artery of Adamkiewicz during pregnancy. Neurology 1979;29:394-398. 


\section{Neurology}

Clinical Reasoning: A 36-Year-Old Woman Presenting With Headache Postpartum Ahmad Nehme, Laurent Létourneau-Guillon, Céline Odier, et al.

Neurology 2021;96;e1585-e1589 Published Online before print December 4, 2020

DOI 10.1212/WNL.0000000000011318

This information is current as of December 4, 2020

Updated Information \& Services

References

Subspecialty Collections

Permissions \& Licensing

Reprints including high resolution figures, can be found at: http://n.neurology.org/content/96/11/e1585.full

This article cites 9 articles, 6 of which you can access for free at: http://n.neurology.org/content/96/11/e1585.full\#ref-list-1

This article, along with others on similar topics, appears in the following collection(s):

All Cerebrovascular disease/Stroke

http://n.neurology.org/cgi/collection/all_cerebrovascular_disease_strok e

All Spinal Cord

http://n.neurology.org/cgi/collection/all_spinal_cord

Carotid artery dissection

http://n.neurology.org/cgi/collection/carotid_artery_dissection Stroke in young adults

http://n.neurology.org/cgi/collection/stroke_in_young_adults

Subarachnoid hemorrhage

http://n.neurology.org/cgi/collection/subarachnoid_hemorrhage

Information about reproducing this article in parts (figures,tables) or in its entirety can be found online at:

http://www.neurology.org/about/about_the_journal\#permissions

Information about ordering reprints can be found online:

http://n.neurology.org/subscribers/advertise

Neurology ${ }^{\circledR}$ is the official journal of the American Academy of Neurology. Published continuously since 1951, it is now a weekly with 48 issues per year. Copyright (C 2020 American Academy of Neurology. All rights reserved. Print ISSN: 0028-3878. Online ISSN: 1526-632X.

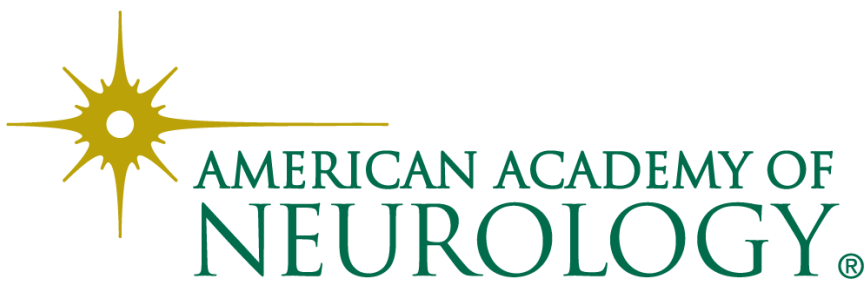

